\title{
REDUCTION OF FOSSIL FUEL USE AND ADOPTION OF ALTERNATIVE ENERGY SOURCES
}

\author{
G. Egberts, A. Voss \\ Programmgruppe Systemforschung und Technologische \\ Entwicklung, Kernforschungsanlage Jülich GmbH, \\ Postfach 1913, D-5170 Jülich 1, West Germany
}

\begin{abstract}
Reduction of carbon dioxide emissions means a much more radical change in the energy supply structure than any possibly successful strategy to replace scarce petroleum could ever be. Moreover, the vulnerability of oil supplies leads to problem solutions, which even aggravate the carbon dioxide problem. Therefore, any improvements must heavily rely on forced energy saving and enhanced use of renewable and nuclear energy. Although the theoretical potential to substitute carbon - and hydrocarbon - fuels has the rather high value of about $2 / 3$ of final energy demand, the technical and economical feasibility of alternative fuels must be judged much more pessimistically. Some recent results of an analysis sponsored by the IEA show, that nuclear and renewable energy supplies may only be able to sustain about $50 \%$ of the growth or primary energy demand of the IEA-countries. Thus, if we want to be sure of having enough energy to sustain our lifestyle, we must not expect reductions of carbon dioxide emissions. This can only be achieved by huge efforts in energy saving, connected with a full utilization of the nuclear and renewable resources.
\end{abstract}

\section{INTRODUCTION}

The energy supply is by far the greatest man-made source of carbon dioxide. It is obvious, therefore, that the growing energy needs are responsible for the slow but steady increase of the equilibrium concentration of carbon dioxide in the atmosphere. Thus, if we do not want to further perturb the carbon dioxide cycle, the logical procedure would be a considerable reduction of carbon use for energy supplies. This implies 
a radical change of our energy system to non-fossil sources, whether they are renewable or not. Such a change would be forced anyway, sooner or later, by the finite extent of fossil energy resources.

\section{ALTERNATIVE ENERGY SYSTEMS FOR REDUCTION OP FOSSIL FUEL USE}

One might doubt to what extent such a substitution process could be feasible in a foreseeable time period. The experiences after the oil crisis justify a certain scepticism. If we did not manage to substitute scarce and expensive oil to a satisfactory extent in the past, how can we expect to make progress to substitute not only for ofl but for all fossil fuels in the future? Even worse, if we can reach a considerable reduction of oil imports, it seems most likely that the carbon dioxide situation becomes even more aggravated. The reason is that a reduction of oil product consumption will only partially be achieved by energy saving. A great deal will be met by substitutes, such as electricity or products from coal conversion. But these are produced much less efficiently and usually from sources with a higher carbon content. This is shown in Pigure 1 for motor fuel, useful energy for heating and electricity (1) :

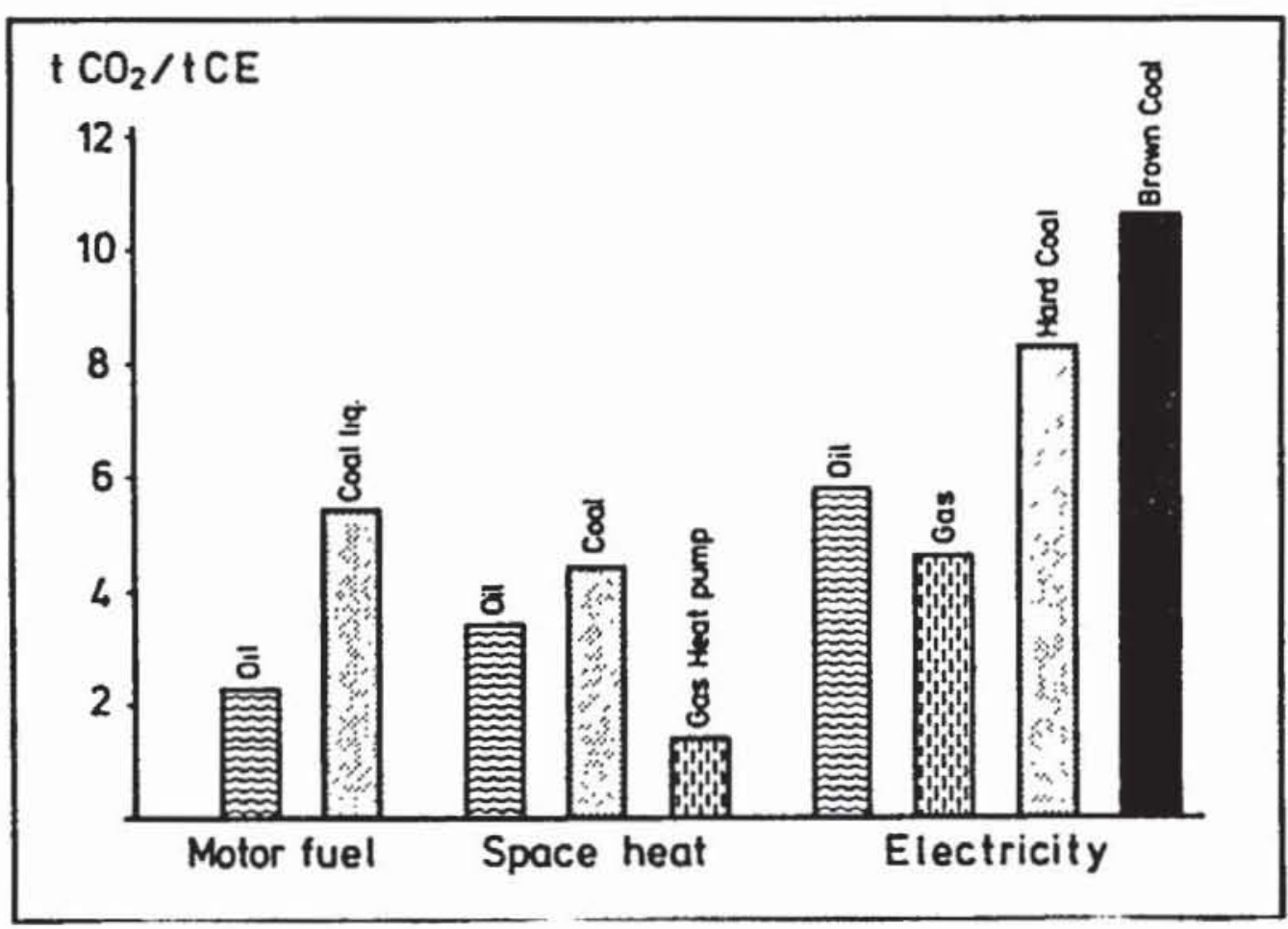

Pig. 1: Carbon dioxide emissions to produce selected final energy forms 
A substitution of oil by coal products leads to a considerable increase of carton dioxide emissions, in some cases more than two times as much. Natural gas supplies are also rather restricted and gas prices are more or less tied to oil prices. So, if we want to save oil and reduce carbon dioxide, we cannot stick to conventional measures. Instead new technologies and new sources must be utilized to a great extent. These are energy saving, renewable and nuclear energy.

One of the most important advantages of fossil fuels, especially oil products, is the very high specific energy content of the fuel. This has economic and technical advantages for transportation and storage of energy. Thus a shift away from fossil fuel will be accompanied by a far reaching change of the infrastructure for transportation and distribution of energy. Technically, a large part of the final enerEy demand based on fossil fuels at present could be met by electricity produced from nuclear or renewable sources. But the needs for energy atorage will require a certain fraction of chemically bound energy anyway. This must mainly be supplied by hydrogen in a real post-carbon future. If we add local hot water distribution systems for heating, fed by coupled production plants and synthetic hydrocarbons based on biomass, we get the following picture of an imaginary post-carbon energy supply structure:

Energy Sources:

-Solar

-Biomass

-Geothermal

-Nuclear

-Energy Saving

Energy Carriers:

-Electricity

-Hot Water

-Hydrogen

-Hydrocarbons from Biomass

In principle all energy services could be met by those secondary energy carriers. Electricity is able to meet all energy demands in the same way as hydrogen does. Hot water is restricted to space heating and warm water generation, whereas fuels from biomass, such as ethanol or methanol, could mainly be used for individual transportation. Going one step further one can imagine a more distant future mainly based on nuclear fission or fusion, where practically all energy demands are met by electricity or hydrogen. 
3. POSSIBILITIES OP FOSSIL FUEL SUBSTITUTION IN THE OECD COUNTRIES

If we restrict ourselves to the foreseesble future, we can surmise that we will not be able to substitute carbon-based fuels in the sectors of non-energy use and individual transportation to a satisfactory degree. Since these sectors are heavily dependent on fluid hydrocarbons for both chemical and physical reasons, we can expect that a substitution, if possible, will concentrate on the other sectors of energy demand. A glance at the present structure of energy demand and supply of the OECD countries shows that demands for non-energy use and transportation form only about $7 \%$ and $25 \%$ respectively of the total final energy demand. Thus, from the viewpoint of the technical nature of the enerES utilization systems, about two thirds of the final energy demand could be from non-fossil sources. The question is, whether we are able to develop such sources to the necessary degree.

Considering the energy resources we are relying on at present, our task becomes obvious; we have to substitute oil, but not by a regression to older and less efficient technologies, such as coal conversion. Since such a strategy would lead to a considerable aggravation of the carbon dioxide problem, we are forced to look forward for new unconventional problem solutions. One of the most attractive ways out of this dilemma could be the direct conversion of solar light into hydrogen and hydrocarbons by means of biological catalysts. Genetic engineering, the scientific and technological challenge of the next decades, is likely to provide an important contribution to a stable, efficient and clean solution to the energy problem. However, this area of research has just been opened, everything is still in the laboratory stage, but the problems we are faced with are urgent at the moment (2).

To get an idea of the possible development of the energy system to a reasonable degree in a reasonable time frame, reference can be made to a study performed by the International Bnergy Agency. This work has been carried out in co-operation with the member countries of the agency in order to elaborate common recommendations for a co-ordinated research and development policy within the OECD to replace the scarce oil (3).

The resulting quantities and structures of future energy supplies of this study shall be taken here as an example of a conceivable or possible future of energy supplies in the restern hemisphere. The general objective of this study was to estimate the possibilities for oil substitution within a general economic framework but without any care about environmental factors. 
Using a linear optimization model of energy supply and utilization, the development over the next forty years of all national energy economies involved in that project has been investigated individually (4). For a certain, well defined set of scenarios only those system developments are determined, which lead to minimal system costs of energy supply over the whole time period of consideration. The optimal mix of technologies and energy carriers resulting from such calculations can give valuable information about the relative virtues and shortcomings of energy technologies. This may be used as a guideline for a goal-orientated technology policy. The starting point of the calculations is the year 1980. The structure of the 15 OECD-countries, which participated in the project so far is shown in Table 1:

Table 1: Projected energy supply structure of 15 IEA-countries IEJ = 34.12 Mio $t$ Coal Equivalent

\begin{tabular}{lccccc}
\hline & Coal & Oil & Gas & $\begin{array}{l}\text { Hydro/ } \\
\text { Nuclear }\end{array}$ & Electricity \\
\hline $\begin{array}{l}\text { Primary } \\
\text { Consumption }\end{array}$ & 31.0 & 75.0 & 28.0 & 16.0 & \\
$\begin{array}{l}\text { Input to } \\
\text { Conversion/Losses }\end{array}$ & 22.0 & 13.5 & 2.5 & 16.0 & \\
$\begin{array}{l}\text { Pinal } \\
\text { Consumption }\end{array}$ & 9.0 & 61.6 & 25.5 & & 15.0 \\
$\begin{array}{l}\text { Traffic } \\
\begin{array}{l}\text { Non energy use } \\
\text { Industry }\end{array}\end{array}$ & 8.0 & 11.0 & 14.5 & & 0.5 \\
$\begin{array}{l}\text { Residential } \\
\text { \& Commercial }\end{array}$ & 1.0 & 13.5 & 9.5 & & 7.0 \\
\hline
\end{tabular}

These 15 countries, namely USA, Japan, Canada, New Zealand and western Europe except France, Portugal and the Netherlands, form, at present, about two thirds of the oil demand of noncommunist countries. It can be seen that mineral oil covers about 50\% of the primary energy demand. Coal and gas have a fraction of about $20 \%$ each.

The assumptions for an unperturbed development yield the follow- 
ing optimized supply structure for the year 2000 (5). The scenario shown in Pigure 2 is based on the rather optimistic assumption of an average growth of final energy demand of about $2 \%$ per annum. This growth is predominantly met by coal and nuclear energy, whereas the use of oil and gas remains approximately constant over time. So within this framework the dependence on crude oil is reduced from about $50 \%$ now to about one third in the next 20 years. This is achieved by the relative substitution of oil products in the end use, especially the industrial and residential sectors. No liquid substitute can gain a market share.

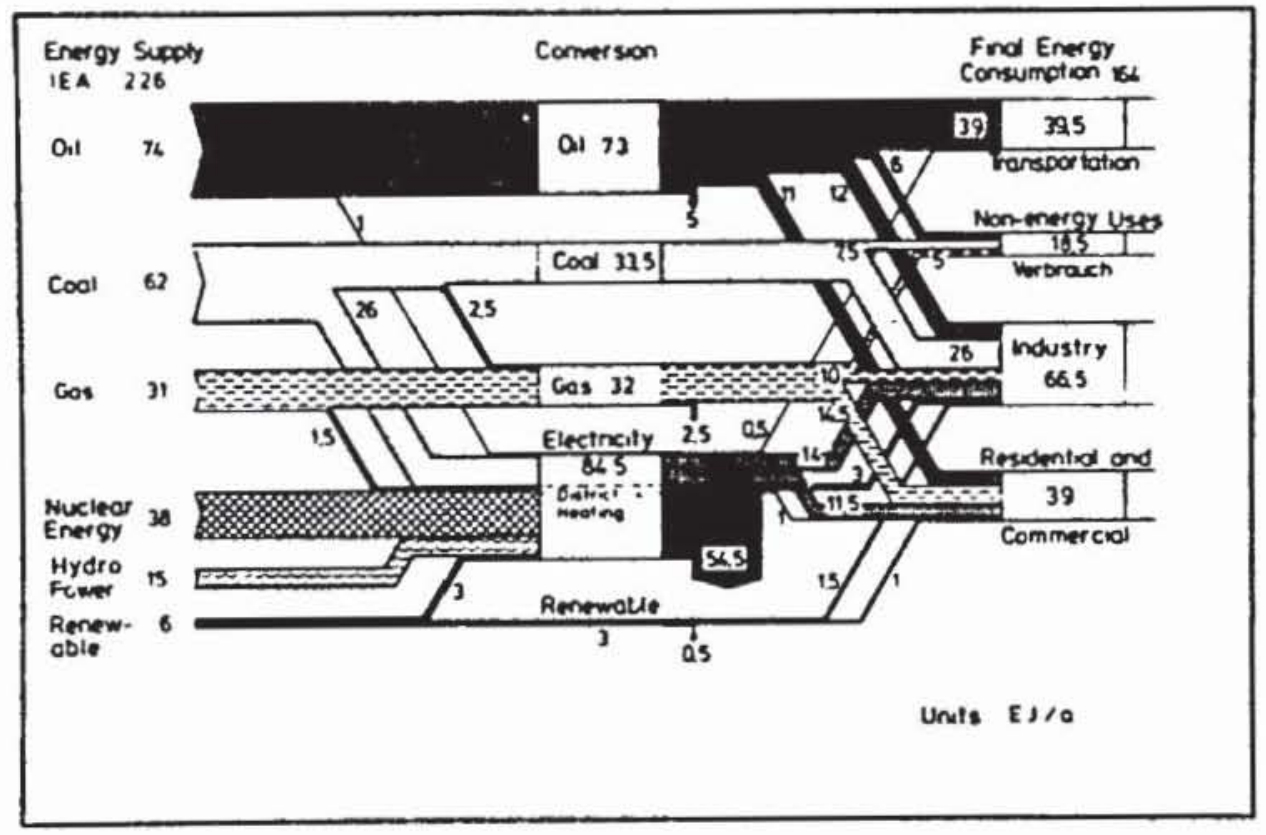

Pig. 2: Optimized energy supply structure of 15 IEA-countries for the year 2000, - Base case -

Since a constant level of oil consumption over time does not seem very satisfactory, a set of strategy runs assuming a forced reduction of oil imports has been performed. The system configuration in the year 2000 over the whole planning period is shown in Figure 3.

Here, oil inputs are reduced to about one quarter of the total primary energy demand. The substitution is mainly made by coal, nuclear and renewables. A small amount of coal liquefaction enters the market first. But again the main part of oil saving and substitution is achieved in the consumption sectors. Here, heat pumps and industrial co-generation have the greatest importance as technologies for ofl substitution. 


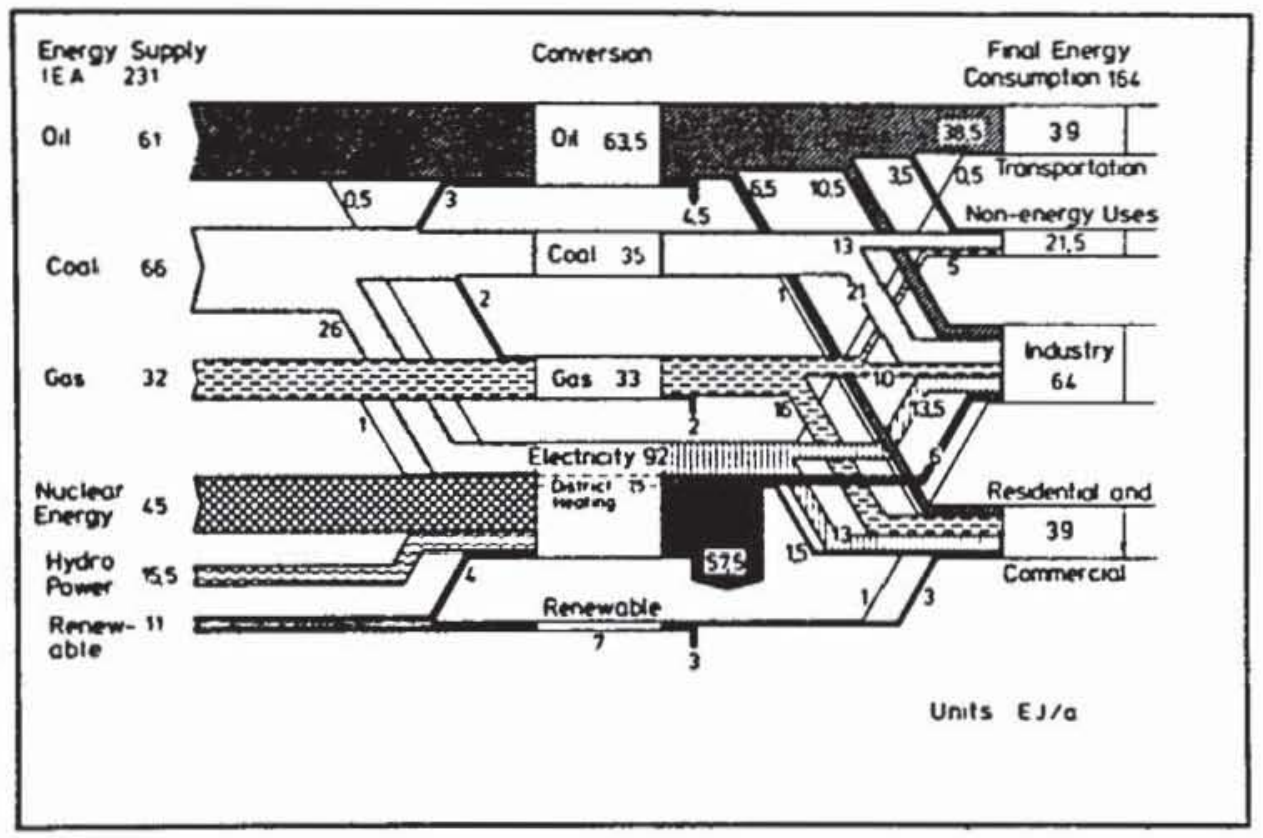

Fig. 3: Optimized energy supply structure of 15 IEA-countries for the year 2000, - Forced oil saving -

Pigure 4 gives an idea of the impacts of those scenarios on the carbon dioxide cycle. These are the total carbon dioxide emissions of the energy supply systems we are dealing with in billion of tons per year. The base case shows an increase of emissions of about $70 \%$ over the planning period. The case of forced oil reduction shows a slight reduction in carb on dioxide emissions too. This is due to the fact that in our model calculations enerEy saving turned out to be more important for oil saving than substitution by synthetic fuels. As a comparison the hypothetical cases are drawn, where all nuclear and all renewables are replaced by coal. These two upper lines can give an idea of the relative importance of both nuclear and renewable energy for the carbon dioxide emissions.

\section{CONCLUSIONS}

Thus, we can conclude that an improvement of the carbon dioride situation is rather unlikely. As this diagram shows, even with optimistic assumptions about energy demand growth and the availability of alternative sources, emissions turned out to show a considerable growth. Thus, even if nuclear and renewable energy can help us a great deal, none of these sources are sufficient. Success can only be obtained by the use of all measures and it seems that the most important one will be an extensive energy saving by more efficient equipment and a new lifestyle, conscious of scarcities. 


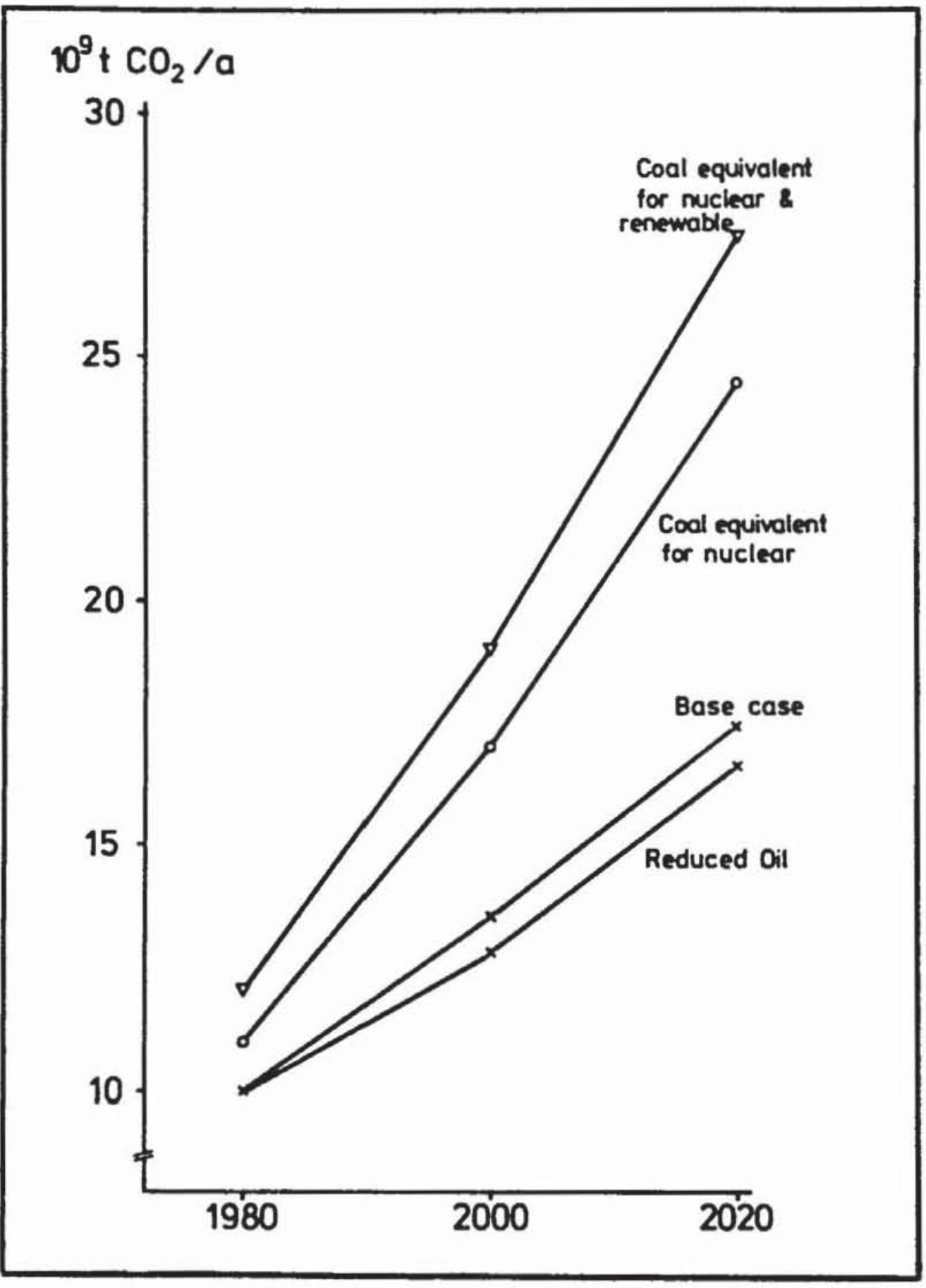

Fig. 4: Carbon dioxide emissions resulting from model calculations for 15 IEA-countries 


\section{REFERENCES}

1. F. Niehaus

Langzeitaspekte der Umweltbelastung durch Energieerzeugung: $\mathrm{CO}_{2}$ und $\mathrm{H}^{3}$ Jul - 1165; Jilich 1975

2. P. Böger

Photobiologische Umwandlung der Sonnenenergie

Naturwissenschaften 65, pp. 407 - 412

Springer-Verlag 1978

3. Annual Report on Energy Research, Development and

Demonstration - Activities of the IEA 1977-1978

IEA, Paris 1979

4. G. Egberts

MARKAL - A multi-period linear optimization model of the energy supply system

Julich 1980 (to be published)

5. Beckurts, K. $-\mathrm{H}$.

Einsatzmöglichkeiten und Substitutionspotential der

Kernenergie

Deutsches Atomforum; Mainz 1980 